\title{
Risk Factors for Preterm Birth and Low Birth Weight Among Pregnant Indian Women: A Hospital-based Prospective Study
}

\author{
Chaitanya Tellapragada ${ }^{1}$, Vandana Kalwaje Eshwara ${ }^{2}$, Parvati Bhat ${ }^{3}$, Shashidhar Acharya ${ }^{4}$, Asha Kamath ${ }^{5}$, \\ Shashikala Bhat ${ }^{3}$, Chythra Rao ${ }^{5}$, Sathisha Nayak ${ }^{3}$, Chiranjay Mukhopadhyay ${ }^{2}$ \\ ${ }^{1}$ Directorate of Research (Health Sciences), Manipal University, Manipal; ${ }^{2}$ Department of Microbiology, Kasturba Medical College, \\ Manipal University, Manipal; ${ }^{3}$ Department of Obstetrics and Gynecology, Melaka Manipal Medical College, Manipal University, Manipal; \\ ${ }^{4}$ Department of Community Dentistry, Manipal College of Dental Sciences, Manipal University, Manipal; ${ }^{5}$ Department of Community Medicine, \\ Kasturba Medical College, Manipal University, Manipal, India
}

Objectives: The present study was undertaken to study the maternal risk factors for preterm birth (PTB) and low birth weight (LBW) with a special emphasis on assessing the proportions of maternal genitourinary and periodontal infections among Indian women and their association with adverse pregnancy outcomes.

Methods: A hospital-based prospective study comprising 790 pregnant women visiting the obstetrics clinic for a routine antenatal check-up was undertaken. Once recruited, all study participants underwent clinical and microbiological investigations for genitourinary infections followed by a dental check-up for the presence of periodontitis. The study participants were followed up until their delivery to record the pregnancy outcomes. Infectious and non-infectious risk factors for PTB and LBW were assessed using univariate and multivariate Cox regression analysis. Independent risk factors for PTB and LBW were reported in terms of adjusted relative risk (ARR) with the $95 \%$ confidence interval (CI).

Results: Rates of PTB and LBW in the study population were $7.6 \%$ and $11.4 \%$, respectively. Previous preterm delivery (ARR, 5.37; 95\% $\mathrm{Cl}, 1.5$ to 19.1 ), periodontitis (ARR, 2.39; $95 \% \mathrm{Cl}, 1.1$ to 4.9 ), Oligohydramnios (ARR, 5.23; 95\% Cl, 2.4 to 11.5), presence of Nugent's intermediate vaginal flora (ARR, 2.75; $95 \% \mathrm{Cl}, 1.4$ to 5.1), gestational diabetes mellitus (ARR, 2.91; $95 \% \mathrm{Cl}, 1.0$ to 8.3 ), and maternal height $<1.50 \mathrm{~m}$ (ARR, 2.21;95\% Cl, 1.1 to 4.1) were risk factors for PTB, while periodontitis (ARR, 3.38; 95\% Cl, 1.6 to 6.9), gestational hypertension (ARR, 3.70;95\% Cl, 1.3 to 10.8), maternal height $<1.50 \mathrm{~m}(\mathrm{ARR}, 2.66 ; 95 \% \mathrm{Cl}, 1.3$ to 5.1$)$ and genital infection during later stages of pregnancy (ARR, $2.79 ; 95 \% \mathrm{Cl}, 1.2$ to 6.1 ) were independent risk factors for $\mathrm{LBW}$.

Conclusions: Our study findings underscore the need to consider screening for potential genitourinary and periodontal infections during routine antenatal care in developing countries.

Key words: Bacteriuria, Bacterial vaginosis, Intermediate vaginal flora, Low birth weight, Periodontitis, Premature birth

\section{INTRODUCTION}

Received: February 22, 2016 Accepted: May 19, 2016

Corresponding author: Vandana Kalwaje Eshwara, MD

Manipal, Karnataka 576104, India

Tel: +91-820-2923171, Fax: +91-820-2593214

E-mail: vandanake@gmail.com

This is an Open Access article distributed under the terms of the Creative Commons Attribution Non-Commercial License (http://creativecommons.org/licenses/bync/3.0/) which permits unrestricted non-commercial use, distribution, and reproduction in any medium, provided the original work is properly cited.
Preterm birth (PTB) is an obstetric complication of complex etiology associated with significant neonatal mortality and morbidity worldwide. Numerous morbidities among infants born preterm have been reported to lead to both neonatal mortality and late sequelae such as respiratory distress syndrome, retinopathy of prematurity, neurological and neurodevelopmental abnormalities, and lifelong vision and hearing impairment [1]. Globally, more than 20 million infants are born 
every year with a birth weight less than $2500 \mathrm{~g}$, with Asia and Africa witnessing the largest numbers. India alone accounts for $40 \%$ of the cases of low birth weight (LBW) in the developing world, and more than half of those in Asia [2]. Various maternal demographic, behavioral, and clinical characteristics have been associated with PTB including maternal race/ethnicity, maternal age at either extreme, cigarette smoking, low pre-pregnancy weight, psychosocial stress, previous PTB, and maternal intrauterine infections [3]. An association of bacterial vaginosis (BV) and periodontitis with adverse pregnancy outcomes has been reported among women belonging to various ethnic groups and geographical locations [4-7]. Despite substantial evidence suggesting the positive association of these infections with adverse pregnancy outcomes from elsewhere, routine screening of pregnant women for genital and periodontal infections is not a common practice in developing countries such as India. Considering the overall paucity of information regarding the risk factors for adverse pregnancy outcomes among Indian women, we undertook the present study to assess the magnitude of maternal infectious and noninfectious parameters and their association with PTB and LBW among a cohort of pregnant women.

\section{METHODS}

\section{Study Site, Design, and Population}

A prospective cohort study was carried out at a secondary care hospital in South India for a period of three years (May 2011 to April 2014). The study was approved by the institutional ethics committee of Kasturba Hospital, Manipal (no. IEC160/2010). Pregnant women aged 18 to 35 years and with a gestational age of 8 to 24 weeks visiting the Obstetrics Clinic for a routine antenatal check-up were invited to participate in the study. Pregnant women with medical diseases such as diabetes mellitus, hypertension, hypo/hyperthyroidism; obstetrical complications such as placenta previa, cervical cerclage, uterine fibroids, twin pregnancy; lifestyle habits such as smoking and consumption of alcohol; or infections such as HIV and syphilis were not included in the study. The sample size was calculated anticipating a prevalence of lower genital infections and periodontitis among $30 \%$ of the study population, a $10 \%$ prevalence of PTB and a relative precision of $25 \%$. It was estimated that a sample of 756 women was needed to show a statistically significant association of maternal genitourinary tract and periodontal infections with PTB and LBW among the target study population.

After written informed consent for study enrollment had been obtained, structured interviews were carried out to gather data regarding socioeconomic, demographic, relevant medical, and obstetric history. Gestational age was estimated based on the date of the last menstrual period, followed by a confirmation using ultrasonography. The body mass index (BMI) of the study participants was calculated based on their weight $(\mathrm{kg})$ and height $(\mathrm{m})$ recorded during the study recruitment. Based on their BMl, women were classified as underweight (BMI $\left.\leq 19.9 \mathrm{~kg} / \mathrm{m}^{2}\right)$, normal weight $\left(20.0-24.9 \mathrm{~kg} / \mathrm{m}^{2}\right)$, overweight $\left(25.0-29.9 \mathrm{~kg} / \mathrm{m}^{2}\right)$, and obese $\left(\geq 30.0 \mathrm{~kg} / \mathrm{m}^{2}\right)$.

\section{Testing for Genitourinary and Periodontal Infections}

A clean catch mid-stream urine specimen was collected from each study participant during recruitment. Urine specimens were subjected to semi-quantitative microbiological culture using cysteine lactose electrolyte-deficient media. Bacterial isolates with significant counts (>105 CFU/mL) were identified up to the species level and antimicrobial susceptibility testing for the isolates was tested and reported as per the Clinical and Laboratory Standards Institute guidelines. Women diagnosed with urinary tract infections (UTI) and/or asymptomatic bacteriuria $(A B)$ were treated with a pathogen-specific antimicrobial agent. All the study participants underwent per speculum examination, during which high vaginal and endocervical swabs were collected for the microbiological diagnosis of lower genital tract infections such as BV, vulvovaginal candidiasis (VVC), trichomoniasis, and genital chlamydiasis. Diagnosis of BV was made by examination of Gram-stained high vaginal smears using Nugent's scoring system (NSS) [8]. Other forms of vaginitis were diagnosed using a wet mount examination of the vaginal secretions for trichomoniasis and Gram-stained smear examination of the high vaginal swabs for VVC. Decisions regarding the treatment for vaginal infections and the choice of an antimicrobial agent for treatment was made by the obstetrician based on the clinical examination alone in the present study. DNA from the endocervical swab was extracted using a QIAamp DNA mini kit (Qiagen $\mathrm{GmbH}$, Hilden, Germany) as per the manufacturer's instructions. The extracted DNA was used for detection of Chlamydia trachomatis. The oligonucleotide primers and the polymerase chain reaction mixture and conditions used in our study targeted the detection of a 201-bp region of the cryptic plasmid 
of $C$. trachomatis as described previously [9]. A detailed periodontal examination was performed using the Community Periodontal Index (CPI) scoring system at the time of recruitment. A pathological pocket depth of at least $4 \mathrm{~mm}$ (CPI score $\geq 3$ ) among any one of the six index teeth examined was diagnostic for periodontitis [10]. Women diagnosed with periodontitis were not provided any form of treatment (antibiotics or scaling) in the present study.

\section{Follow-up of Study Participants and Pregnancy Outcomes}

Study participants were followed for the rest of their gestational period, and the occurrence of any adverse event(s) such as late pregnancy loss between 20 weeks and 24 weeks of gestation, gestational diabetes, gestational hypertension, intrauterine growth restriction, threatened preterm labor, UTI, symptomatic genital infections during later stages of pregnancy, and oligohydroamnios were recorded. PTB was considered to be any birth occurring before the completion of 37 weeks of gestation. LBW was considered to be a birth weight of less than $2500 \mathrm{~g}$. Infants born preterm with LBW were considered to be preterm low birth weight (PLBW). For the final analysis to assess the risk factors for PTB, PLBW, and LBW among the study population, data regarding the infectious and non-infectious parameters of 710 women was included.

\section{Statistical Analysis}

Subject information was digitized and analyzed using the SPSS version 16.0 (SPSS South Asia Pvt. Ltd., Bangalore, India). The proportion of cases with maternal genitourinary and periodontal infections were estimated using descriptive statistics. The incidence density per 1000 person-weeks of gestation for PTB and LBW were estimated among the present study cohort. The chi-square test was used for the comparison of baseline and infectious parameters among the members of the study population with follow-up data available and those that were lost during follow-up. The association of infectious and non-infectious maternal parameters with adverse pregnancy outcomes was estimated in terms of crude relative risk (CRR) with a $95 \%$ confidence interval $(\mathrm{Cl})$ using univariate Cox regression. Using forward Wald multivariate Cox regression, risk factors for PTB, PLBW, and LBW were assessed separately after adjusting for the maternal baseline, physical, and infectious covariates. Ultimately, independent risk factors with adjusted relative risk (ARR) and $95 \% \mathrm{Cl}$ were reported.

\section{RESULTS}

A total of 790 women were recruited for the study. The mean age of the study population was $27.18 \pm 3.54$ years. The mean gestational age of the study population at inclusion was $14 \pm$ 4.2 weeks. The majority of the study subjects completed at least 12 years of schooling $(n=518,65 \%)$ and $69 \%(n=550)$ of them had a monthly household income of $>10000$ Indian rupees (INR). The mean height of the study population was $1.55 \pm 0.05 \mathrm{~m}$ (range, 1.35 to $1.72 \mathrm{~m}$ ). The majority ( $n=506$, $64 \%$ ) of the study participants had a normal BMI. Slightly more than half ( $n=461,58 \%$ ) of the study participants were primi gravida. Among the 329 women who had had a previous pregnancy, $110(33.4 \%)$ reported a history of abortion. Prior history of preterm delivery was reported among 10/219 (4.5\%) of the women. A detailed description of the baseline characteristics among the study population is presented in Table 1.

Using NSS, BV (Nugent's score, 7 to 10) was diagnosed among 48 (6\%) of the women. Further, 108 (13.6\%) women were found to have intermediate vaginal flora (Nugent's score, 4 to 6). VVC and trichomoniasis were observed among 97 $(12.2 \%)$ and 94 (11.8\%) women, respectively. None of the women tested were positive for $C$. trachomatis. Significant bacteriuria was observed in 57 (7.2\%) women. Of these 57 women, AB was observed among 20 (35\%) and the other 37 $(65 \%)$ women had clinical symptoms of UTI. Among women with significant bacteriuria, Escherichia coli was the leading pathogen, in $42(75 \%)$ of the cases, followed by Klebsiella pneumoniae in nine (16\%). From the other five women, Enterococcus spp. was isolated in four (7\%) and Proteus mirabilis in one (2\%). Nitrofurantoin (52\%) and cefixime (45\%) were the most commonly prescribed antibiotics for treatment of significant bacteriuria. Overall, the proportion of women with $A B$ in the present study population was $2.5 \%$ at the time of testing. Periodontitis was diagnosed in 90 (11.3\%) women using CPI scoring. The proportion of maternal genitourinary and periodontal infections among the study population is detailed in Table 1.

Pregnancy outcomes for 64 (8\%) women were not available for the final analysis, as these women were lost to follow-up during the study. A detailed description of the study participants that were lost during follow-up is provided in Table 1. Among the 726 women with follow-up data available, adverse events such as late pregnancy loss $(n=16,2.2 \%)$, gestational diabetes mellitus $(n=38,5.2 \%)$, gestational hypertension $(n=$ 
Table 1. Comparison of baseline characteristics between study participants with follow-up loss and follow-up completion $(n=790)$

\begin{tabular}{|c|c|c|c|c|}
\hline Baseline characteristics & Proportion & Follow-up completed ( $n=726$ ) & Follow-up lost (n=64) & $p$-value \\
\hline \multicolumn{5}{|l|}{ Religion } \\
\hline Hindu & $694(87.8)$ & $639(88.0)$ & $55(85.9)$ & 0.27 \\
\hline Christian & $62(7.8)$ & $55(7.5)$ & $7(10.9)$ & \\
\hline Muslim & $34(4.3)$ & $32(4.4)$ & $2(3.1)$ & \\
\hline \multicolumn{5}{|l|}{ Occupation } \\
\hline Homemaker & $651(82.4)$ & $603(83.0)$ & $48(75.0)$ & 0.13 \\
\hline Working & $139(17.5)$ & $123(16.9)$ & $16(25.0)$ & \\
\hline \multicolumn{5}{|l|}{ Monthly income (INR) } \\
\hline$<5000$ & $41(5.1)$ & $34(4.6)$ & $7(10.9)$ & 0.60 \\
\hline $5001-10000$ & $199(25.1)$ & $187(25.7)$ & $12(18.7)$ & \\
\hline $10001-15000$ & $166(21.0)$ & $154(21.2)$ & $12(18.7)$ & \\
\hline$>15000$ & $384(48.6)$ & $351(48.3)$ & $33(51.5)$ & \\
\hline \multicolumn{5}{|l|}{ Level of education } \\
\hline$<7$ years of schooling & $272(34.4)$ & $245(33.7)$ & $27(42.0)$ & 0.49 \\
\hline $7-12$ years of schooling & $330(41.7)$ & $309(42.5)$ & $21(34.0)$ & \\
\hline High school graduate \& above & $188(23.7)$ & $172(23.6)$ & $16(24.0)$ & \\
\hline \multicolumn{5}{|l|}{ Parity index } \\
\hline Primigravida & $461(58.3)$ & $422(58.1)$ & $39(60.9)$ & 0.87 \\
\hline Second gravida & $261(33.0)$ & $243(33.4)$ & $18(28.1)$ & \\
\hline Third gravida & $68(8.6)$ & $61(8.4)$ & $7(11.0)$ & \\
\hline \multicolumn{5}{|l|}{ Maternal age (y) } \\
\hline $20-24$ & $194(24.5)$ & $177(24.3)$ & $17(26.5)$ & 0.38 \\
\hline $25-29$ & $395(50.0)$ & $369(50.8)$ & $26(40.6)$ & \\
\hline $30-35$ & $201(25.5)$ & $180(24.7)$ & $21(32.8)$ & \\
\hline \multicolumn{5}{|l|}{ Maternal height (m) } \\
\hline$<1.50$ & $146(18.4)$ & $130(17.9)$ & $16(25.0)$ & 0.12 \\
\hline$\geq 1.50$ & $644(81.5)$ & $596(82.0)$ & $48(75.0)$ & \\
\hline \multicolumn{5}{|l|}{ Maternal BMI at first visit } \\
\hline Normal & $506(64.0)$ & $471(64.8)$ & $35(54.6)$ & 0.08 \\
\hline Underweight & $197(25.0)$ & $178(24.5)$ & $19(29.6)$ & \\
\hline Overweight & $78(9.8)$ & $70(9.6)$ & $8(12.5)$ & \\
\hline Obese & $9(1.1)$ & $7(0.9)$ & $2(3.1)$ & \\
\hline \multicolumn{5}{|l|}{ Bacterial vaginosis } \\
\hline Present & $48(6.0)$ & $42(5.7)$ & $6(9.3)$ & 0.17 \\
\hline Absent & $742(94.0)$ & $684(94.3)$ & $58(90.6)$ & \\
\hline \multicolumn{5}{|l|}{ Vulvovaginal candidiasis } \\
\hline Present & $97(12.2)$ & $86(11.8)$ & $11(17.1)$ & 0.33 \\
\hline Absent & $693(87.8)$ & 640 (88.2) & $53(82.8)$ & \\
\hline \multicolumn{5}{|l|}{ Trichomoniasis } \\
\hline Present & $94(11.8)$ & $86(11.8)$ & $8(12.5)$ & 1.00 \\
\hline Absent & $696(88.2)$ & $640(88.2)$ & $56(87.5)$ & \\
\hline \multicolumn{5}{|l|}{ Nugent's grade II flora } \\
\hline Present & $108(13.6)$ & $101(13.9)$ & $7(10.9)$ & 0.57 \\
\hline Absent & $682(86.3)$ & $625(86.0)$ & $57(89.0)$ & \\
\hline \multicolumn{5}{|l|}{ Urinary tract infection } \\
\hline Present & $57(7.2)$ & $50(6.8)$ & $7(10.9)$ & 0.31 \\
\hline Absent & 733 (92.8) & $676(93.2)$ & $57(89.0)$ & \\
\hline \multicolumn{5}{|l|}{ Periodontitis } \\
\hline Present & $90(11.3)$ & $83(11.4)$ & $7(10.9)$ & 0.22 \\
\hline Absent & $700(88.6)$ & $643(88.5)$ & $57(89.0)$ & \\
\hline
\end{tabular}

Values are presented as number (\%).

INR, Indian rupees; BMI, body mass index. 
$22,3 \%)$, UTI ( $n=23,3.1 \%)$, symptomatic genital infections during the later stages of pregnancy $(n=65,8.9 \%)$, and oligohydramnios ( $n=31,4.2 \%$ ) were observed. Among the 710 women with a successful pregnancy, 54 (7.6\%) women experienced preterm delivery. The mean gestational age of the women that delivered at term and preterm in the present study were $38.5 \pm 0.8$ and $35.6 \pm 2.3$ weeks, respectively. LBW was observed among 81 (11.4\%) babies born in the study. The mean birth weight of the babies born was $2971 \pm 438.75 \mathrm{~g}$. Among the 81 infants born with LBW, 34 (42\%) of them were born preterm, and intrauterine growth restriction was observed in 11 (13.5\%). Overall, the incidence densities of PTB and LBW among the study population were $3.2(95 \% \mathrm{Cl}, 2.8$ to 3.5$)$ and $4.9(95 \% \mathrm{Cl}, 4.6$ to 5.2$)$ per 1000 person-weeks of gestation, respectively.

Further, presence of more than one of the three infections, namely, periodontitis, BV, and intermediate vaginal flora, was observed in 34/710 (4.7\%) women. Preterm delivery and LBW were observed among $23.5 \%(n=8)$ and $35.2 \%(n=12)$, respectively, of the 34 women with more than one infection ( $p<$ $0.001)$, as compared to $10.4 \%(n=15)$ and $15.2 \%(n=22)$ of the 144 women with only one of the three infections. Using univariate Cox regression, we observed a significant association of maternal height less than $1.50 \mathrm{~m}$, history of previous preterm delivery, gestational hypertension, oligohydramnios, BV, and periodontitis with PTB and/or LBW. Other maternal baseline characteristics such as BMI, level of education, monthly household income, and parity index did not have an association with adverse pregnancy outcomes. A detailed description of the association of maternal physical, demographic, and infectious parameters with PTB, PLBW, and LBW among the study population is provided in Table 2 .

Independent risk factors for PTB in the present study population were previous preterm delivery (ARR, 5.37; 95\% Cl, 1.5 to 19.1), periodontitis (ARR, 2.39; $95 \% \mathrm{Cl}, 1.1$ to 4.9 ), Oligohydramnios (ARR, 5.23; 95\% Cl, 2.4 to 11.5), presence of Nugent's intermediate vaginal flora (ARR, 2.75; $95 \% \mathrm{Cl}, 1.4$ to 5.1 ), gestational diabetes mellitus (ARR, 2.91; $95 \% \mathrm{Cl}, 1.0$ to 8.3 ), and maternal height $<1.50 \mathrm{~m}$ (ARR, $2.21 ; 95 \% \mathrm{Cl}, 1.1$ to 4.1 ). Similarly, independent risk factors for LBW were periodontitis (ARR, 3.38; $95 \% \mathrm{Cl}, 1.6$ to 6.9 ), gestational hypertension (ARR, 3.70; $95 \% \mathrm{Cl}, 1.3$ to 10.8 ), maternal height $<1.50 \mathrm{~m}$ (ARR, 2.66; $95 \%$ $\mathrm{Cl}, 1.3$ to 5.1$)$, and genital infections during the later stages of pregnancy (ARR, 2.79; $95 \% \mathrm{Cl}, 1.2$ to 6.1). Independent risk factors for PTB, PLBW, and LBW in the study population are pre- sented in Table 3.

\section{DISCUSSION}

PTB is a prevalent obstetric complication associated with significant neonatal mortality and morbidity worldwide. Addressing the burden of PTB in developing countries is of public health importance due to its high (9 to $16 \%$ ) prevalence. Though the exact etiopathogenesis of PTB is still unclear, in developing nations, prediction and/or diagnosis of this multifactorial process is made mainly based on the evidence reported in the western literature on the risk factors and probable pathological mechanisms $[3,11,12]$. More recently, reports suggesting the disparity in risk factors for PTB due to ethnic/ racial influences among women underscored the need for assessing the risk factors at both inter-national and intra-national levels to formulate interventions to reduce the burden of PTB. Given this context, the present study was undertaken to elucidate the infectious and non-infectious risk factors for PTB and LBW among Indian pregnant women seeking routine antenatal care at a secondary care hospital.

The PTB rate of $7.6 \%$ observed in the present study population is lower as compared to the estimates (15\%) reported by the World Health Organization among Indian women [13]. Similarly, we observed a lower rate (11.4\%) of LBW in our study population as compared to previous reports from other parts of the country $[14,15]$. The low rates of PTB and LBW in the present study as compared to the previous reports from other parts of the country could be attributed to the target study population for the following reasons: i) The present study was carried out in Udupi district, which is considered to be one of the more developed districts in the state of Karnataka, India [16]. ii) The study population consisted of young women (mean age, $27.18 \pm 3.5$ years) with higher levels of education. iii) The majority of the study participants belonged to the middle income group (>10 $000 \mathrm{INR} / \mathrm{mo}$ ), unlike the other studies, which had higher rates of PTB and LBW among women belonging to the low income group and those with lower literacy [13-15]. iv) Further, to avoid the confounding effect of other known risk factors for PTB, in the present study we excluded the recruitment of women with a history of smoking, consumption of alcohol, twin and multiple pregnancy, pregestational diabetes mellitus, and hypertension.

While PTB is well acknowledged as a multifactorial process, ascending genital tract infections have previously been impli- 
Table 2. Association of maternal physical, demographic, and infectious parameters with PTB, PLBW, and LBW in the study population $(\mathrm{n}=710)$

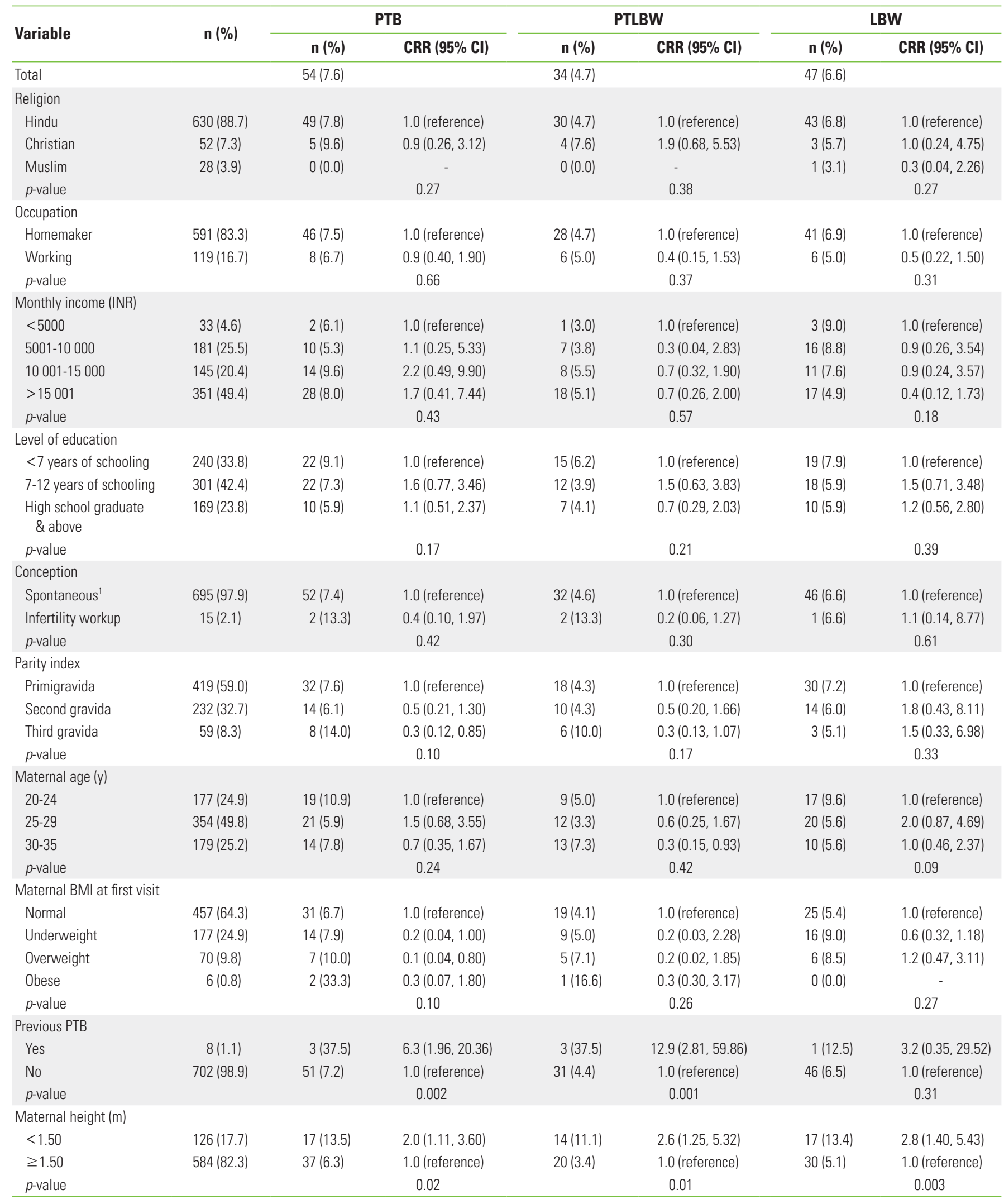




\section{Journal of}

Preventive Medicine \& Public Health

Table 2. Continued from the previous page

\begin{tabular}{|c|c|c|c|c|c|c|c|}
\hline \multirow{2}{*}{ Variable } & \multirow{2}{*}{ n (\%) } & \multicolumn{2}{|c|}{ PTB } & \multicolumn{2}{|c|}{ PTLBW } & \multicolumn{2}{|c|}{ LBW } \\
\hline & & n (\%) & CRR (95\% CI) & n (\%) & CRR $(95 \%$ CI) & n (\%) & CRR $(95 \%$ CI) \\
\hline \multicolumn{8}{|c|}{ Bacterial vaginosis } \\
\hline Present & $42(5.9)$ & $7(16.7)$ & $3.2(1.02,10.41)$ & $6(14.2)$ & $1.8(0.60,5.37)$ & $5(11.9)$ & $1.4(0.53,4.16)$ \\
\hline Absent & $668(94.1)$ & $47(7.0)$ & 1.0 (reference) & $28(4.1)$ & 1.0 (reference) & $42(6.2)$ & 1.0 (reference) \\
\hline$p$-value & & & 0.05 & & 0.06 & & 0.17 \\
\hline \multicolumn{8}{|l|}{ VVC } \\
\hline Present & $84(11.8)$ & $7(8.3)$ & $0.8(0.34,2.08)$ & $4(4.7)$ & $0.7(0.24,2.27)$ & $6(7.1)$ & $0.8(0.34,2.16)$ \\
\hline Absent & $626(88.2)$ & $47(7.5)$ & 1.0 (reference) & $30(4.7)$ & 1.0 (reference) & $41(6.5)$ & 1.0 (reference) \\
\hline$p$-value & & & 0.71 & & 0.92 & & 0.81 \\
\hline \multicolumn{8}{|c|}{ Trichomoniasis } \\
\hline Present & 84 (11.8) & $5(5.9)$ & $0.3(0.08,1.57)$ & $3(3.5)$ & $0.9(0.28,3.22)$ & $3(3.5)$ & $0.3(0.08,1.56)$ \\
\hline Absent & $626(88.2)$ & $49(7.8)$ & 1.0 (reference) & $31(4.9)$ & 1.0 (reference) & $44(7.0)$ & 1.0 (reference) \\
\hline$p$-value & & & 0.18 & & 0.41 & & 0.35 \\
\hline \multicolumn{8}{|c|}{ Nugent's grade II flora } \\
\hline Present & $78(11.0)$ & $13(16.6)$ & $1.1(0.45,2.81)$ & $11(14.0)$ & $0.4(0.17,1.10)$ & $7(8.9)$ & $0.9(0.40,2.44)$ \\
\hline Absent & $632(89.0)$ & $41(6.5)$ & 1.0 (reference) & $23(3.6)$ & 1.0 (reference) & $40(6.3)$ & 1.0 (reference) \\
\hline$p$-value & & & 0.78 & & 0.006 & & 0.66 \\
\hline \multicolumn{8}{|c|}{ Urinary tract infection } \\
\hline Present & $48(6.8)$ & $3(6.2)$ & $1.2(0.39,4.18)$ & $3(6.2)$ & $1.5(0.47,5.30)$ & $3(6.2)$ & $0.8(0.38,4.16)$ \\
\hline Absent & 662 (93.2) & $51(7.7)$ & 1.0 (reference) & $31(4.6)$ & 1.0 (reference) & $44(6.6)$ & 1.0 (reference) \\
\hline$p$-value & & & 0.68 & & 0.69 & & 0.87 \\
\hline \multicolumn{8}{|c|}{ Periodontitis } \\
\hline Present & $81(11.4)$ & $11(13.5)$ & $3.4(1.73,6.93)$ & $8(9.8)$ & $2.8(1.26,6.49)$ & $12(14.8)$ & $3.4(1.71,6.80)$ \\
\hline Absent & $629(88.6)$ & $43(6.8)$ & 1.0 (reference) & $24(3.8)$ & 1.0 (reference) & $35(5.5)$ & 1.0 (reference) \\
\hline$p$-value & & & $<0.001$ & & 0.001 & & 0.003 \\
\hline \multicolumn{8}{|c|}{ Gestational hypertension } \\
\hline Present & $22(3.0)$ & $6(11.1)$ & $3.3(1.15,9.56)$ & $3(13.6)$ & $3.5(1.52,8.44)$ & $4(18.1)$ & $3.0(1.28,7.07)$ \\
\hline Absent & $688(97.0)$ & $49(7.1)$ & 1.0 (reference) & $31(4.5)$ & 1.0 (reference) & $43(6.2)$ & 1.0 (reference) \\
\hline$p$-value & & & 0.02 & & 0.001 & & 0.02 \\
\hline \multicolumn{8}{|c|}{ Oligohydramnios } \\
\hline Present & $31(4.3)$ & $8(25.8)$ & $4.8(2.24,10.63)$ & $7(22.5)$ & $2.7(1.07,6.93)$ & $4(12.9)$ & $5.6(2.91,10.84)$ \\
\hline Absent & $679(95.6)$ & $46(6.7)$ & 1.0 (reference) & $27(3.9)$ & 1.0 (reference) & $43(6.3)$ & 1.0 (reference) \\
\hline$p$-value & & & $<0.001$ & & $<0.001$ & & 0.05 \\
\hline \multicolumn{8}{|c|}{ Gestational diabetes mellitus } \\
\hline Present & $38(5.3)$ & $4(10.5)$ & $1.9(0.67,5.59)$ & $3(7.9)$ & $1.2(0.37,3.93)$ & $2(5.2)$ & $1.7(0.69,4.42)$ \\
\hline Absent & $672(94.6)$ & $50(7.4)$ & 1.0 (reference) & $31(4.6)$ & 1.0 (reference) & $45(6.6)$ & 1.0 (reference) \\
\hline$p$-value & & & 0.34 & & 0.47 & & 1.00 \\
\hline \multicolumn{8}{|c|}{ UTI during follow-up } \\
\hline Present & $23(3.1)$ & $3(13.0)$ & $1.2(0.38,4.25)$ & $1(4.3)$ & $0.6(0.15,2.75)$ & $0(0.0)$ & $0.2(0.30,1.76)$ \\
\hline Absent & $687(96.9)$ & $51(7.4)$ & 1.0 (reference) & $33(4.8)$ & 1.0 (reference) & $47(6.8)$ & 1.0 (reference) \\
\hline$p$-value & & & 0.41 & & 0.87 & & 0.39 \\
\hline \multicolumn{8}{|c|}{ Gl during follow-up } \\
\hline Present & $65(9.1)$ & $6(9.2)$ & $1.3(0.55,3.13)$ & $2(3.0)$ & $0.7(0.17,3.13)$ & $9(13.8)$ & $2.0(1.05,3.81)$ \\
\hline Absent & $645(90.8)$ & $48(7.4)$ & 1.0 (reference) & $32(4.9)$ & 1.0 (reference) & $38(5.8)$ & 1.0 (reference) \\
\hline$p$-value & & & 0.45 & & 0.13 & & 0.01 \\
\hline
\end{tabular}

The CRR was determined using Cox regression analysis.

PTB, preterm birth; PTLBW, preterm low birth weight; LBW, low birth weight; CRR, crude relative risk; Cl, confidence interval; INR, Indian rupees; BMI, body mass index; VVC, vulvovaginal candidiasis; UTI, urinary tract infection; GI, genital infection. 
Table 3. Independent risk factors for PTB, PTLBW, and LBW in the study population

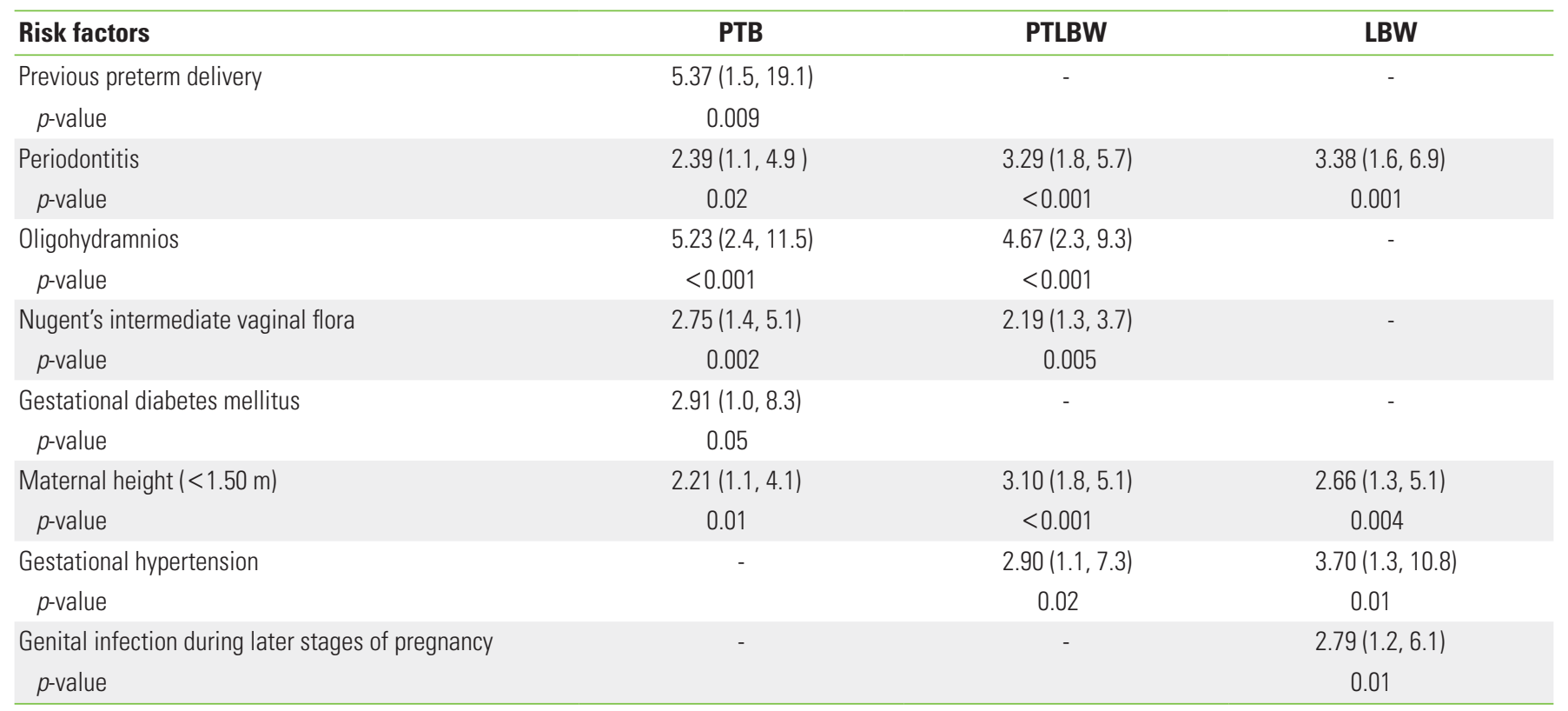

Value are presented as adjusted relative risk ( $95 \%$ confidence interval). The relative risk was calculated using the Cox proportional hazard model and estimated after adjusting for age, level of education, parity, monthly household income, and maternal body mass index in the study population.

PTB, preterm birth; PTLBW, preterm low birth weight; LBW, low birth weight.

cated in at least half of the cases. In particular, the causal relationship between BV and PTB among women from various ethnic groups has been consistently noted. A few studies have reported the magnitude of BV during pregnancy among Indian women (6.4\% [17], 24.3\% [18], and 12\% [19]); however, the paucity of data regarding the potential association of $\mathrm{BV}$ with PTB among these women is evident in the published literature. A lower rate of BV (6\%) could possibly be attributed to the socioeconomic and lifestyle factors of our study population. BV was reported to be high among women from low socioeconomic strata, and those with low levels of education, a history of smoking, and multiple sex partners [20-22], while our study population not fit this description. Further, none of the previously reported studies from India could be matched with our cohort in terms of the sample size and gestational age at the time of testing. With the overall low proportion of women with BV $(48 / 790,6 \%)$ and further loss of six women diagnosed with $\mathrm{BV}$ on follow-up, the present study had relatively a small cohort of 42 women with BV for the final outcome analysis. In this context, the finding of BV not being an independent risk factor for PTB and LBW in the present study population is not surprising. Nevertheless, a positive association of BV with PTB as observed using univariate Cox regression in the present study population underscores the need for future studies using a larger sample size to understand the causal relationship in Indian women.

Other forms of vaginal infection like VVC and trichomoniasis were more commonly observed than $\mathrm{BV}$ in the present study. However, neither VVC nor trichomoniasis had any statistically significant association with PTB or LBW among the women in this study. These findings are similar to those reported previously among women belonging to other ethnic groups $[23,24]$. The causal relationship between intermediate vaginal flora and adverse pregnancy outcomes has been increasingly emphasized in the past two decades $[25,26]$. While the exact mechanism by which the presence of these intermediate vaginal flora could lead to PTB is unknown, inflammatory responses primarily due to the abundance of IL1 and IL6 were reported to mediate the production of prostaglandins and cause preterm uterine contractions [27]. In the present cohort, women with Nugent's intermediate vaginal flora were found to be at 2.7 times greater risk for preterm delivery than women with normal vaginal flora. To the best of our knowledge, this is the first report suggesting a positive association of intermediate vaginal flora in pregnant Indian women with PTB and PTLBW.

Of the total of 57 (7.1\%) women diagnosed with $A B$ and UTI during their first visit, 55 (97\%) of them received specific anti- 
biotic therapy, and none of them developed complications like pyelonephritis. Previously from a meta-analysis, it was reported that treatment of $A B$ and UTI among pregnant women was a useful intervention to avoid complications like pyelonephritis and its associated adverse pregnancy outcomes like PTB and LBW [28]. From a prospective study among North Indian pregnant women, no association between $A B$ diagnosed early during pregnancy and adverse pregnancy outcomes was reported [29]. We attribute the lack of association of $A B$ and UTI with PTB and LBW in the present study to early diagnosis and effective antibiotic treatment. Based on the current study's findings, we recommend the routine screening of pregnant women for the presence of $A B$ during their early pregnancies as a cost-effective intervention to avoid further complications.

The proportion of periodontitis in the present study's population $(11.6 \%)$ is slightly lower than the overall prevalence (14\% to $18 \%$ ) of the disease reported in the adult population of India [30]. This is likely due to our study population comprising women in younger age groups from the middle and upper middle income category, and non-smokers [31,32]. Previously, a decrease in the incidence of PTB was reported among Indian pregnant women who underwent treatment for periodontitis [7]. However, considering the significance of periodontitis as an independent risk factor for both PTB and LBW, as observed in the present study, we emphasize the need for further studies to determine whether early diagnosis and treatment ( $<20$ weeks of gestation) of these subtle infections can show a reduction in rates of PTB and LBW.

While women with pre-gestational hypertension were excluded from recruitment in the present study, 22 (3\%) of the 726 women developed gestational hypertension (after 20 weeks of gestation), which was found to be an independent risk factor for PTB and LBW. A similar association of gestational hypertension was reported among various study populations globally $[1,12,33]$. Oligohydramnios (amniotic fluid index $<5$ $\mathrm{cm}$ ) during the third trimester of pregnancy was diagnosed in 31 (4.3\%) of the women. A similar association of oligohydramnios with adverse pregnancy outcomes as observed in our study was reported previously $[11,34]$. A positive association of genital infections (diagnosed based on clinical signs and symptoms alone in the present study) during later stages of pregnancy with LBW suggests the need for future longitudinal studies to assess the implications of changes in the vaginal microbioma during different stages of pregnancy for adverse pregnancy outcomes.

We acknowledge a few limitations of our study. The rate of infections reported in our study represented the proportion of women infected during their early stages of pregnancy only. Considering the homogenous nature of our study population and variation in the rates of these infections due to the socioeconomic and behavioral characteristics of the study population, the rates of infections reported in the present study cannot be generalized to pregnant women with diverse demographic characteristics. The attrition rate of $8 \%$ in the study population was also one of our limitations. However, the study findings deduced from women with follow-up data available can be extrapolated to those that were lost to follow-up, as the two groups did not differ significantly in terms of their baseline characteristics and infectious parameters. Screening for the presence of genitourinary and periodontal infections could not be repeated during the later stages of pregnancy in the present study due to resource constraints. If only this could be done, we could have estimated the proportion of women developing new or recurrent infections during the later stages of pregnancy. Despite these limitations, our study findings add significant insight on the role of asymptomatic maternal infections such as intermediate vaginal flora and periodontitis on adverse pregnancy outcomes. These findings have important implications for settings where infection screening is not a routine practice during antenatal care.

\section{ACKNOWLEDGEMENTS}

This study was supported by an Ad-hoc Research Grant (no. 2009-03350) from the Indian Council of Medical Research, New Delhi, India.

\section{CONFLICT OF INTEREST}

The authors have no conflicts of interest associated with the material presented in this paper.

\section{ORCID}

Chaitanya Tellapragada http://orcid.org/0000-0002-01175369

Vandana Kalwaje Eshwara http://orcid.org/0000-0001-75614435 


\section{REFERENCES}

1. Blencowe $H$, Cousens $S$, Chou D, Oestergaard M, Say L, Moller $A B$, et al. Born too soon: the global epidemiology of 15 million preterm births. Reprod Health 2013;10 Suppl 1:S2.

2. United Nations Children's Fund; World Health Organization. Low birthweight: country, regional and global estimates; 2004 [cited 2016 May 28]. Available from: http://www.unicef. org/publications/files/low_birthweight_from_EY.pdf.

3. Chan RL. Biochemical markers of spontaneous preterm birth in asymptomatic women. Biomed Res Int 2014;2014:164081.

4. Paige DM, Augustyn M, Adih WK, Witter F, Chang J. Bacterial vaginosis and preterm birth: a comprehensive review of the literature. J Nurse Midwifery 1998;43(2):83-89.

5. Svare JA, Schmidt H, Hansen BB, Lose G. Bacterial vaginosis in a cohort of Danish pregnant women: prevalence and relationship with preterm delivery, low birthweight and perinatal infections. BJOG 2006;113(12):1419-1425.

6. Offenbacher S, Boggess KA, Murtha AP, Jared HL, Lieff S, McKaig RG, et al. Progressive periodontal disease and risk of very preterm delivery. Obstet Gynecol 2006;107(1):29-36.

7. Tarannum F, Faizuddin M. Effect of periodontal therapy on pregnancy outcome in women affected by periodontitis. J Periodontol 2007;78(11):2095-2103.

8. Nugent RP, Krohn MA, Hillier SL. Reliability of diagnosing bacterial vaginosis is improved by a standardized method of gram stain interpretation. J Clin Microbiol 1991;29(2):297301.

9. Mahony JB, Luinstra KE, Sellors JW, Jang D, Chernesky MA. Confirmatory polymerase chain reaction testing for Chlamydia trachomatis in first-void urine from asymptomatic and symptomatic men. J Clin Microbiol 1992;30(9):2241-2245.

10. World Health Organization. Oral health surveys: basic methods. 3rd ed. Geneva: World Health Organization; 1987.

11. Goldenberg RL, Goepfert AR, Ramsey PS. Biochemical markers for the prediction of preterm birth. Am J Obstet Gynecol 2005;192(5 Suppl):S36-S46.

12. Zhang YP, Liu XH, Gao SH, Wang JM, Gu YS, Zhang JY, et al. Risk factors for preterm birth in five Maternal and Child Health hospitals in Beijing. PLoS One 2012;7(12):e52780.

13. Vogel JP, Lee AC, Souza JP. Maternal morbidity and preterm birth in 22 low- and middle-income countries: a secondary analysis of the WHO Global Survey dataset. BMC Pregnancy Childbirth 2014;14:56.

14. Thomre PS, Borle AL, Naik JD, Rajderkar SS. Maternal risk fac- tors determining birth weight of newborns: a tertiary care hospital based study. Int J Recent Trends Sci Technol 2012;5 (1):3-8.

15. Mumbare SS, Maindarkar G, Darade R, Yenge S, Tolani MK, Patole K. Maternal risk factors associated with term low birth weight neonates: a matched-pair case control study. Indian Pediatr 2012;49(1):25-28.

16. Nair NS, Rao RS, Chandrashekar S, Acharya D, Bhat HV. Sociodemographic and maternal determinants of low birth weight: a multivariate approach. Indian J Pediatr 2000;67(1):9-14.

17. Balamurugan SS, Bendigeri N. Community-based study of reproductive tract infections among women of the reproductive age group in the urban health training centre area in hubli, karnataka. Indian J Community Med 2012;37(1):34-38.

18. Laxmi U, Agrawal S, Raghunandan C, Randhawa VS, Saili A. Association of bacterial vaginosis with adverse fetomaternal outcome in women with spontaneous preterm labor: a prospective cohort study. J Matern Fetal Neonatal Med 2012;25 (1):64-67.

19. Mittal V, Jain A, Pradeep Y. Development of modified diagnostic criteria for bacterial vaginosis at peripheral health centres in developing countries. J Infect Dev Ctries 2012;6(5):373-377.

20. Koumans EH, Sternberg M, Bruce C, McQuillan G, Kendrick J, Sutton $M$, et al. The prevalence of bacterial vaginosis in the United States, 2001-2004; associations with symptoms, sexual behaviors, and reproductive health. Sex Transm Dis 2007;34 (11):864-869.

21. Larsson PG, Fåhraeus L, Carlsson B, Jakobsson T, Forsum U. Predisposing factors for bacterial vaginosis, treatment efficacy and pregnancy outcome among term deliveries; results from a preterm delivery study. BMC Womens Health 2007;7:20.

22. Misra DP, Trabert B. Vaginal douching and risk of preterm birth among African American women. Am J Obstet Gynecol 2007;196(2):140.e1-140.e8.

23. Klebanoff MA, Carey JC, Hauth JC, Hillier SL, Nugent RP, Thom $E A$, et al. Failure of metronidazole to prevent preterm delivery among pregnant women with asymptomatic Trichomonas vaginalis infection. N Engl J Med 2001;345(7):487-493.

24. Giraldo PC, Araújo ED, Junior JE, do Amaral RL, Passos MR, Gonçalves AK. The prevalence of urogenital infections in pregnant women experiencing preterm and full-term labor. Infect Dis Obstet Gynecol 2012;2012:878241.

25. Carey JC, Klebanoff MA. Is a change in the vaginal flora associated with an increased risk of preterm birth? Am J Obstet Gynecol 2005;192(4):1341-1346. 
26. Donders GG, Van Calsteren K, Bellen G, Reybrouck R, Van den Bosch T, Riphagen I, et al. Predictive value for preterm birth of abnormal vaginal flora, bacterial vaginosis and aerobic vaginitis during the first trimester of pregnancy. BJOG 2009;116 (10):1315-1324.

27. Donati L, Di Vico A, Nucci M, Quagliozzi L, Spagnuolo T, Labianca $A$, et al. Vaginal microbial flora and outcome of pregnancy. Arch Gynecol Obstet 2010;281(4):589-600.

28. Smaill F, Vazquez JC. Antibiotics for asymptomatic bacteriuria in pregnancy. Cochrane Database Syst Rev 2007;(2):CD000490.

29. Jain V, Das V, Agarwal A, Pandey A. Asymptomatic bacteriuria \& obstetric outcome following treatment in early versus late pregnancy in north Indian women. Indian J Med Res 2013;137 (4):753-758.

30. Murthy S, Mubashir A, Kodkany BS, Mallapur MD. Pregnancy periodontitis and low birth weight: a cohort study in rural Belgaum, India. Glob J Med Public Health 2012;1(4):42-48.

31. Kimura S, Ooshima T, Takiguchi M, Sasaki Y, Amano A, Morisaki I, et al. Periodontopathic bacterial infection in childhood. J Periodontol 2002;73(1):20-26.

32. Vogt M, Sallum AW, Cecatti JG, Morais SS. Factors associated with the prevalence of periodontal disease in low-risk pregnant women. Reprod Health 2012;9:3.

33. Yadav $\mathrm{H}$, Lee N. Maternal factors in predicting low birth weight babies. Med J Malaysia 2013;68(1):44-47.

34. Kim BJ, Romero R, Mi Lee S, Park CW, Shin Park J, Jun JK, et al. Clinical significance of oligohydramnios in patients with preterm labor and intact membranes. J Perinat Med 2011;39(2): 131-136. 